\title{
Ensino médio no Brasil \\ A formação docente desde 1990
}

\author{
Sônia Maria Pereira de Lima* \\ Maria Andreia Andrade* \\ MARIA InÊS SUCUPIRA STAMATto***
}

\begin{abstract}
RESUMO: $\mathrm{O}$ artigo apresenta uma análise realizada nos referenciais curriculares nacionais do ensino médio (Dcnem, Pcnem, Ocnem, Enem, Plano Nacional de Formação de Professores), bem como na Lei de Diretrizes e Bases da Educação Nacional (Ldben) e no Plano Nacional de Educação 2014-2024 (PNE), com o objetivo de endossar o debate acerca da trajetória das mudanças curriculares que vêm sendo propostas para o ensino médio, da década de 1990 aos dias atuais, e, em especial, para compreender como esses documentos vêm situando a formação de professores, dada sua relevância para o desenvolvimento profissional.
\end{abstract}
Palavras-chave: Ensino médio. Referenciais curriculares. Formação docente.

\section{High school education in Brazil \\ Teacher formation since 1990}

\footnotetext{
* Mestranda em Educação. Atualmente é professora técnica do ensino médio na Gerência Regional de Educação do Agreste Meridional (GRE-AM Garanhuns), onde exerce atividades de coordenação Regional e formadora do Programa Ensino Médio Inovador (programa financiado pelo MEC e monitorado com a parceria da SEE-PE) em escolas de educação integral e semi integral jurisdicionadas a GRE/AM. É formadora na área de Ciências Humanas para professores do Ensino Médio e Integra o Grupo de Estudos em Gestão Escolar da Universidade Federal Rural de Pernambuco - Unidade Garanhuns (UAG/UFRPE). Garanhuns/ PE - Brasil. E-mail: <sonia.lima2013@yahoo.com.br>.

** Mestranda em Educação. Membro do grupo de pesquisa: Formação e Profissionalização Docente da Universidade Federal do Rio Grande do Norte (UFRN/Capes) e tem 15 anos de experiencia de docência no ensino de Química e Biologia voltado ao ensino médio. Natal/RN - Brasil. E-mail: <m.andreia.maa@gmail.com>.

*** Doutora em História. É professora Titular da Universidade Federal do Rio Grande do Norte e do Programa de Pós-Graduação - no Mestrado e Doutorado - em Educação (PPGED/UFRN). Também é vice-líder do Grupo de Pesquisa História da Educação, Literatura e Gênero/diretório do CNPq, e coordenadora dos projetos de pesquisa "Livro Didático: História do ensino de História no Brasil (1808-2008)" e "A Lei e a Escola: uma história da escola no Brasil (1808-2008)". Natal/RN - Brasil. E-mail: <stamattoines@gmail.com>.
} 


\begin{abstract}
The article presents an analysis carried out on the national curricular frameworks for high school education (Dcnem, Penem, Ocnem, Enem, the National Plan for teacher formation), as well as the Law, Directives and Bases for National Education (Ldben) and also on the National Education Plan - PNE (2014-2024). The objective is to endorse the debate on the direction of the proposed changes for high school education, from the 1990's to the present time, and especially, to understand how these documents regard teacher formation, given their relevance for teachers' professional development.
\end{abstract}

Key words: High school education. Curricular frameworks. Teacher formation.

\title{
Enseñanza media en Brasil
}

La formación docente desde 1990

RESUMEN: El artículo presenta un análisis de los modelos curriculares nacionales de referencia de la enseñanza media (Dcnem, Pcnem, Ocnem, Enem, Plan Nacional de Formación de Profesores), de la Ley de Directrices y Bases de la Educación Nacional (Ldben) y del Plan Nacional de Educación 2014-2024 (PNE), con el objetivo de refrendar el debate acerca de la trayectoria de los cambios curriculares que se han propuesto para la enseñanza secundaria desde la década de 1990 hasta la actualidad, y especialmente comprender cómo esos documentos vienen situando la formación de profesores, dada su importancia para el desarrollo profesional.

Palabras clave: Enseñanza secundaria. Modelos curriculares de referencia. Formación docente.

\section{Enseignement secondaire au Brésil}

La formation des enseignants depuis 1990

RÉSUMÉ: Cet article présente une analyse réalisée dans le cadre des programmes scolaires nationaux de l'enseignement secondaire (Dcnem, Pcnem, Ocnem, Enem, Plano Nacional de Formação de Professores), tout comme dans celui de la Loi des Lignes Direc- 
trices et de Bases de l'Education Nationale (Ldben) et du Plan National d'Education 2014-2024 (PNE), dans le but de valider le débat autour de la trajectoire des changements de programmes scolaires qui ont été proposés pour l'enseignement secondaire, des années 90 à nos jours, et plus particulièrement de comprendre comment ces documents abordent la formation des professeurs, compte tenu de son importance pour l'épanouissement professionnel.

Mots-clés: Enseignement secondaire. Cadre du Porgramme scolaire. Formation des enseignants.

\section{Introdução}

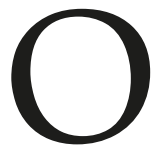

ensino médio - última etapa da educação básica - apresenta, como uma de suas principais finalidades de ensino e de aprendizagem, "a compreensão dos fundamentos científico-tecnológicos dos processos produtivos, relacionando a teoria com a prática no ensino de cada disciplina" (LDBEN, 1996, Art. 35, Inciso IV). Refletir acerca da política educacional brasileira e seu papel na otimização da formação do professor nessa etapa de escolaridade pode ser de grande relevância, pois revela um panorama de como isso vem sendo tratado nas ações de melhoria da qualidade do ensino médio implementadas pelo Ministério da Educação (MEC) às escolas públicas do País.

Este artigo faz uma revisão bibliográfica e documental sobre o ensino médio e expõe os resultados de análise realizada nos referenciais curriculares nacionais do ensino médio (Dcnem, Pcnem, Ocnem, Enem, Plano Nacional de Formação de Professores), bem como na Lei de Diretrizes e Bases da Educação Nacional (Ldben, nº 9.394, de 1996) e no Plano Nacional de Educação (PNE, 2014-2024), com o objetivo de endossar o debate acerca da trajetória de mudanças curriculares que vêm sendo propostas para o ensino médio, da década de 1990 aos dias atuais, e, em especial, para compreender como esses documentos situam a formação de professores, dada sua relevância para o desenvolvimento profissional.

Libânio (2007, p. 30-44) escreve que a formação de professores é essencial para a atuação profissional, na escola do século XXI, pois pode conduzi-lo a atitudes que, materializadas no processo de ensino-aprendizagem, contribuem para a inovação da práxis educativa. Dentre elas,

1 Assumir o ensino como mediação: aprendizagem do aluno com a ajuda do professor; 2 modificar a ideia de uma escola e de uma prática pluridisciplinar para uma escola e uma prática interdisciplinar; 3 conhecer estratégias do ensinar a pensar. Ensinar a aprender a aprender; 5 persistir no empenho de auxiliar os alunos a buscarem uma perspectivas crítica dos conteúdos, a técnica e cultural, 
como ingredientes se habituarem a apreender as realidades enfocadas nos conteúdos escolares de forma crítica-reflexiva; 6 reconhecer o impacto das novas tecnologias da comunicação e informação em sala de aula; 7 investir na atualização científica, técnica e cultural, como ingredientes do processo de formação continuada (grifos nossos).

Por outro lado, para construir tais atitudes, os professores necessitam ter um programa de formação que se fundamente no paradigma da complexidade do conhecimento ${ }^{1}$, que o oportunize a dialogar com as diferentes visões/formas de construir conhecimento, tendo como referência o exercício da reflexão crítica sob a prática, uma vez que, nas palavras de Ramalho et.al (2003, p.31),

a crítica numa perspectiva mais ampla é considerada como uma atitude, uma forma de aproximação, reformulação e recriação da realidade, na qual estão, como elementos básicos, o esforço de conhecimento da realidade, o esforço de superação das práticas iniciais, a reconstrução de ideias próprias tomando como referencias os resultados da pesquisa, dos conhecimentos das disciplinas científicas e as experiências próprias e de outros colegas.

Assim, estamos diante de uma sociedade em constante mudança, que requer profissionais com mais senso de criticidade e autonomia na resolução de problemas de maneira ativa e reflexiva. Nesse caso, conhecer o percurso histórico que a política educacional brasileira vem delineando para a formação docente no ensino médio, desde a década de 1990, pode contribuir para fundamentar a hipótese de que a atualização da prática pedagógica, sobretudo nível de ensino, é inerente ao exercício da atividade docente e, portanto, um dever do sistema e política educacional brasileira para com a formação e profissionalização docente na educação básica.

Partindo desse entendimento, procurou-se responder ao seguinte questionamento: de que forma a politica educacional brasileira tem contemplado nos referenciais curriculares nacionais as necessidades formativas dos professores de ensino médio com vistas à inovação da prática pedagógica?

\section{O currículo do ensino médio da década de 1990 aos dias atuais}

Desde a década de 1990, a educação básica em todas as etapas de escolaridade, especialmente no ensino médio, vem sendo alvo de estudos e de atenção das políticas públicas implementadas no País, no intuito de atender aos desafios de uma educação de qualidade social que priorize as necessidades de aprendizagem dos estudantes e a melhoria da qualidade do ensino, conforme discussão na Conferência Mundial de Educação para Todos, na Tailândia, em 1990, da qual resultou, posteriormente, o Plano de Metas Compromisso Todos pela Educação², instituído pelo Decreto Federal nº 6.094, de 2007. 
É fato, porém, que, já a partir do consenso internacional firmado nessa conferência, algumas mobilizações da política pública brasileira para a educação básica começaram a ser feitas para subsidiar a prática docente pela melhoria da qualidade do ensino e, em especial, do ensino médio. Assim, foi elaborada a Lei de Diretrizes e Bases da Educação Nacional (Ldben, 1996) e sua implementação passou a ser supervisionada pelo Ministério da Educação e Cultura (MEC).

Em relação à prática docente no ensino médio, a Lei trouxe exigências curriculares, dentre estas, a de que o currículo "adotará metodologias de ensino e de avaliação que estimulem a iniciativa dos estudantes" (LDBEN, 1996, Art. 36- Inciso II), demanda a ser contemplada no planejamento do professor. Na mesma linha de pensamento, a Ldben ainda acrescenta no Art.35 (Parágrafo $1^{\circ}$ Incisos I e II) que,

os conteúdos, as metodologias e a formas de avaliação serão organizados de tal forma que ao final do ensino médio o estudante demonstre: domínio dos conhecimentos científicos e tecnológicos que presidem a sociedade moderna; conhecimentos das formas contemporâneas de linguagens.

Diante dessa concepção, a política educacional brasileira deixa clara a necessidade de um processo de ensino-aprendizagem de qualidade social para todos nessa etapa de escolaridade. Para tanto, traz a perspectiva de inovação do ensino a partir do diálogo entre a teoria e a prática e que desperte o estudante para novas iniciativas e novas oportunidades de apropriação do conhecimento, o que requer do professor. além da reflexão da própria prática no cotidiano de sala de aula, uma reflexão também nos campos de sua formação, pois,

a bagagem teórica terá pouca utilidade, se o professor não fizer uma reflexão global sobre sua vida. Como aluno e como profissional. é preciso combater a mera reprodução de práticas de ensino, sem espírito crítico ou esforço de mudança. É preciso estar aberto às novidades e procurar diferentes métodos de trabalho, mas sempre partindo de uma análise individual e coletiva das práticas. (NÓVOA, 1995, 85).

Outro ponto que merece reflexão situa-se no que a Ldben estabelece para os profissionais de educação. Logo que a Lei foi homologada, no Título VI em seu Art. 61, ao se referir aos profissionais de educação, a redação trazia o seguinte: que a formação de profissionais da educação tivesse como fundamento "a associação entre teorias e práticas, inclusive mediante a capacitação e serviço” (LDBEN,1996, Art.61, Inciso I), o que reforçava a necessidade do diálogo entre teoria e prática no processo de ensino-aprendizagem, com vistas ao desenvolvimento integral do estudante, uma vez que,

na sociedade contemporânea, as rápidas transformações no mundo do trabalho, o avanço tecnológico configurando a sociedade virtual e os meios de informação, incidem fortemente na escola, aumentando os desafios para torná-la uma conquista democrática efetiva. [...]. O desafio é educar crianças e jovens, 
propiciando-lhes um desenvolvimento humano, cultural, científico e tecnológico, de modo que adquiram condições para enfrentar o mundo contemporâneo (DELIZOICOV; ANGOTTI; PERNAMBUCO, 2002, p. 12).

Essa questão é considerada de tão grande relevância, que a Ldben nº 9.394, de 1996, ao ser atualizada pela Lei n⿳0 12.014, de 2009, intensificou a necessidade de que a articulação teoria/prática fosse contemplada em todos os momentos da formação dos profissionais da educação básica, especialmente no ensino médio. Nesse sentido, uma nova redação foi atribuída para o Art.61, o qual passou a ter também um Parágrafo Único, constituído de dois incisos, a saber,

a formação dos profissionais da educação de modo a atender às especificidades do exercício de suas atividades, bem como aos objetivos das diferentes etapas e modalidades da educação básica, terá como fundamento:

I a presença de sólida formação básica, que propicie o conhecimento dos fundamentos científicos e sociais de suas competências de trabalho;

II a associação entre teoria e prática mediante estágios supervisionados e capacitação em serviço (Lei nº 12.014, de 2009).

Partindo desse entendimento e ainda em consonância com a LDBEN nº 9.394, de 1996, nas Disposições Transitórias, quando em seu Art. 87 Parágrafo 3º, consta ser de responsabilidade de cada estado e município "realizar programas de capacitação para todos os professores em exercício, utilizando também, para isto, os recursos de educação a distância" (Inciso III) - entende-se que, desde 1990, as mudanças curriculares apontam a formação de professores como instrumento qualitativo para subsidiar a prática docente. E, nesse contexto, um ponto em comum se refere ao atendimento às necessidades formativas dos professores, quer seja presencial ou mesmo via educação a distância. Ramalho e Nuñez (2004, p.73) explicam que,

a formação é um tipo de atividade em que o professor se apropria da cultura profissional e modifica, sob influencias externas pedagogicamente organizadas, elementos chaves do seu agir profissional, de forma a influenciar no desenvolvimento profissional.

Ante o exposto, percebe-se também que a política educacional brasileira, desde a época da criação da Ldben no 9.394, de 1996, tem vislumbrado para o ensino médio novas perspectivas de ensino e de aprendizagem que se adequem ao paradigma de inovação e aos princípios da interdisciplinaridade e contextualização.

Na implementação de referenciais curriculares visando orientar as escolas no planejamento de um ensino que contemple a inovação da práxis educativa, o MEC organizou esses documentos com foco na reestruturação curricular, ação intensificada da década de 2000 aos dias atuais. 
Em 1998 surgem as Diretrizes Curriculares Nacionais para o Ensino Médio (Dcnem, 1998) e com elas se reforça a necessidade de um ensino contextualizado e que tenha a interdisciplinaridade como uma das alternativas pedagógicas, sobretudo nos momentos de formação docente, a fim de que a práxis educativa pautada pelo princípio interdisciplinar seja entendida "como a reflexão e ação dos homens sobre o mundo para transformá-lo" (FREIRE, 1987, p.38), e possa, então, contribuir para a superação de um ensino tradicional (que se caracteriza pela dicotomia entre teoria e prática no ensino médio).

Para orientar os professores do ensino médio em sua organização curricular, o Ministério da Educação envia às escolas essas Diretrizes, as quais definem que o planejamento e a organização pedagógica da escola deve ser conduzida com base numa Matriz curricular, a saber:

\section{Diretrizes Curriculares Nacionais do Ensino Médio (Dcnem) Resolução CEB} no 3, de 1998

\begin{tabular}{lll}
\hline \hline $\begin{array}{l}\text { Organização Curricular do Ensino Médio - Art.10 - A base nacional } \\
\text { comum dos currículos do EM será organizada em áreas de conhecimento, } \\
\text { a saber: }\end{array}$ \\
\hline \hline Linguagens, Códigos e suas & Ciências da Natureza, Matemá- & Ciências Humanas e suas \\
Tecnologias & tica e suas Tecnologias & Tecnologias \\
Língua Portuguesa & Física & História \\
Língua Estrangeira Moderna & Química & Geografia \\
Arte & Biologia & Sociologia \\
Educação Física & Matemática & Filosofia \\
\hline \hline
\end{tabular}

Fonte: BRASIL, MEC/SEB, 1998.

Essas propostas de organização curricular trouxeram para o ensino médio, a perspectiva da contextualização ${ }^{3} \mathrm{e}$, nesse caso, na interdisciplinaridade ${ }^{4}$ com foco, por um lado, no aprofundamento dos conteúdos específicos de cada área, através da utilização de procedimentos didáticos pertinentes aos estudos e, por outro, do incentivo a articulação e conexão interdisciplinar dos conteúdos estudados, em circunstâncias que possam envolver conteúdos tecnológicos e práticos numa perspectiva integradora.

(...) os objetivos do Ensino Médio em cada área do conhecimento deve envolver, de forma combinada, o desenvolvimento de conhecimentos práticos, contextualizados, que, respondam às necessidades da vida contemporânea, e o desenvolvimento de conhecimentos mais amplos e abstratos, que correspondam a uma visão de mundo (PCNEM, 1999,p. 207). 
Diante desses paradigmas, outras iniciativas começaram a ser adotadas pelo Ministério da Educação para atender à melhoria do rendimento escolar e à universalização e expansão do ensino, dentre estas, a reestruturação do ensino médio por meio de programas educacionais de apoio ao desenvolvimento da inovação do processo ensino-aprendizagem, com foco na ampliação de estudos e no redesenho curricular. São necessidades registradas pelas Diretrizes Curriculares Nacionais do Ensino Médio (DCNEM, 2012), sobretudo no que se refere ao incentivo à prática de leitura e à iniciação científica e pesquisa, o que requer do professor formação e qualificação profissional.

\section{Formação e prática docente na atual legislação oficial brasileira}

A democratização do ensino médio e a luta por melhores perspectivas de ensino e aprendizagem para atender a esse redesenho curricular acentuaram o debate acerca da formação continuada, o que induziu a política educacional brasileira a buscar meios de garantir a atualização da prática docente em momentos de formação na educação básica.

É fato que essa mobilização endossou o debate pela democratização do ensino e melhoria do trabalho docente no Brasil. A partir do movimento de luta dos educadores de todo o País por melhores condições do desenvolvimento profissional no ensino médio, o MEC começou a pensar políticas públicas para a reestruturação curricular.

Cabe lembrar que, para um grande número de pesquisadores na área de formação e profissionalização docente [Nóvoa (1995); Tardif et. al (2006); Gatti et. al (2009)], a reestruturação do conhecimento, na década de 1980, teve impacto decisivo em relação aos novos rumos, na década de 1990, das novas perspectivas de ensino e de aprendizagem e as novas concepções de professor-pesquisador contidas nos Pcnem (BRASIL, 1999).

No contexto das proposições encaminhadas pelos Parâmetros Curriculares Nacionais à melhoria da formação de professores, destaca-se a atualização da prática docente pelo viés de uma proposta de formação e ensino com foco no perfil de um professor pesquisador - um dos muitos desafios postos para a formação de professores, desde a década de 90 (PCNEM, 1999) até o contexto atual (DCNEM, 2012).

De 1990 a 2000, enfrentamos desafio de outra ordem, ou seja, através do volume de informações pelas novas tecnologias, a formação do estudante passou a ter como alvo principal a aquisição de conhecimentos básicos, a preparação científica e a capacidade de utilizar as diferentes tecnologias em diversas áreas. Propõe-se, para a etapa do ensino médio, "a formação geral, em oposição à formação específica; o desenvolvimento de capacidades de pesquisar, buscar informações, analisá-las e selecioná-las; a capacidade de aprender, criar, formular, ao invés do simples exercício de memorização" (PCNEM, 2000, p. 88) - o que mais uma vez direcionou o debate nacional do ensino médio para a necessidade de reestruturação curricular. 
A priori, a ideia de reestruturação curricular adveio da necessidade de romper com o paradigma de ensino descontextualizado, que abriga tendências academicistas na prática docente, onde o professor não é produtor de conhecimentos, mas reconhecido como consumidor de saberes profissionais produzidos por especialistas de áreas específicas. Assim, para Ramalho (2003, p.21-22),

\begin{abstract}
a formação docente no Brasil está baseada nas seguintes características: treinamento de habilidades; conteúdos descontextualizados; distancia do objeto da profissão ( processo educativo da escola); evidente dicotomia entre teoria e prática, com o criticado estágio terminal e escassos momentos para mobilizar saberes da profissão na prática real.
\end{abstract}

No período que antecedeu a aprovação da Lei de Diretrizes e Bases da Educação Nacional, em 1996 (Lei Federal nº 9.394, de 1996), os debates sobre a melhoria de desempenho escolar na educação básica (sob os princípios de democracia e cidadania no eixo curricular) já eram prioridade em todos os órgãos educacionais do País. Educadores e sociedade civil apontavam como caminho para qualificação do ensino a vivência, na escola, dos princípios de democratização e autonomia para efetiva uma "educação para todos", conforme expressava a literatura educacional. Weber (2003) acrescenta que

as mudanças educacionais que vêm se inserindo no país desde a década de 1990, tem situado a democratização da educação como necessidade básica para o exercício pleno da cidadania, sendo, portanto um meio de efetivar no processo ensino-aprendizagem uma relação dialógica entre professor, aluno e conhecimento e adaptar a escola as mudanças do mundo do trabalho que caracterizam a sociedade contemporânea (p.1135).

Em decorrência das mudanças no ensino médio com a criação da LDBEN no 9.394, de 1996), da década de 2000 até hoje, há novas perspectivas de ensino e de aprendizagem. Há que ressalvar a revolução tecnológica e as novas exigências à escola por novas formas de socialização, de processos de produção e, até mesmo, novas definições de identidade individual e coletiva.

Por esse ângulo, as Orientações Curriculares Nacionais do Ensino Médio (OCNEM, 2006, p. 58), ao enfatizar que "o ensino precisa ser reinventado e a prática docente atualizada para atender as demandas de ensino e aprendizagem que colocam o estudante na posição de protagonista", apontam que é inerente à atividade profissional docente a formação continuada e inicial, como meio de adequação da prática pedagógica aos novos contextos.

Na perspectiva de um ensino médio que considere o mundo do trabalho e a prática social como elementos essenciais à formação integral do estudante, a política educacional brasileira cria alguns projetos e programas educativos com foco na melhoria da qualidade do ensino. E o debate nacional, entre 2008 e 2009, demonstra a urgência de romper com modelos tradicionais de ensino e aprendizagem, a fim de que a perspectiva 
da aprendizagem permanente (tanto para professores como para estudantes) seja prioridade na formação docente (continuada e inicial).

O MEC, através da Secretaria de Educação Básica (SEB), propõe o Programa Ensino Médio Inovador (ProEMI), através da Portaria no 971, de 9 de outubro de 2009, o qual integra as ações do Plano de Desenvolvimento da Educação (PDE) como estratégia do Governo Federal para induzir ao redesenho curricular do ensino médio. Por esse viés, o programa visa

apoiar as Secretarias Estaduais de Educação e do Distrito Federal no desenvolvimento de ações de melhoria da qualidade do ensino médio não profissionalizante, com ênfase nos projetos pedagógicos que promovam a educação científica e humanística, a valorização da leitura, da cultura, o aprimoramento da relação teoria e prática, da utilização de novas tecnologias e o desenvolvimento de metodologias criativas e emancipadoras (BRASIL, Portaria nํ9 971, de 2009, Art.2²).

Entre outras ações de cunho educativo visando à melhoria da prática docente no ensino médio, esse programa propõe a dinamização dos trabalho dos professores através de novos campos de ação didático-curricular denominados de macrocampos, com a finalidade de "assegurar o fortalecimento e o desenvolvimento de propostas curriculares inovadoras no ensino médio" (BRASIL, 2009, p. 7).

Assim, além de incentivar, através do apoio financeiro ao desenvolvimento de propostas inovadoras nas escolas públicas de ensino médio, esse programa foi criado visando: i) expandir o atendimento e melhorar a qualidade do ensino médio; ii) desenvolver e reestruturar o ensino médio não profissional, de forma a combinar formação geral, científica, tecnológica, cultural e conhecimentos técnico-experimentais; iii) promover e estimular a inovação curricular no ensino médio; iV) incentivar o retorno de adolescentes e jovens ao sistema escolar e proporcionar a elevação da escolaridade; V) fomentar o diálogo entre a escola e os sujeitos adolescentes e jovens. Em todos esses objetivos foram pensados no sentido de que o ensino médio, possa "ofertar uma educação pública de qualidade social como direito fundamental de todas as pessoas, fundamentada no respeito aos direitos humanos, na equidade, na relevância, na pertinência, na eficácia e na eficiência" (UNESCO, 2005).

Com foco no princípio de unidade entre os eixos Trabalho, Ciência, Cultura e Tecnologia no currículo escolar, o Ministério da Educação (MEC) objetiva incentivar as redes estaduais de ensino a apresentarem propostas diversificadas nos diversos componentes curriculares, com vistas a tornar as aulas mais atrativas e com sentido para os jovens matriculados no ensino médio. Assim, a carga horária de estudos é ampliada de 2.400 horas-aula, mínimo exigido por lei, para 3.000 horas-aulas. Essa realidade constitui no Brasil o universo das escolas de tempo integral, para favorecer o desenvolvimento integral do estudante ${ }^{5}$. 
Ao se analisar os documentos orientadores desse programa, percebe-se a lacuna, até o documento orientador de 2013, em relação à formação do professor para atender as novas perspectivas de ensino e aprendizagem através dos novos campos de ação pedagógico-curriculares ${ }^{6}$ delineados pela política educacional brasileira.

O foco da política pública, até 2013, priorizou exclusivamente a aprendizagem do estudante a partir da necessidade de um ensino que articule a produção do conhecimento aos eixos estruturantes do ensino médio (Trabalho, Ciência, Cultura e Tecnologia), tendo nos macrocampos as estratégias didáticas para dinamizar o ensino-aprendizagem.

Ressalta-se, porém, que só no final de 2013, diante dos resultados apresentados pelo Inep em 2013 e pelo Instituto Paulo Montenegro (Nepson) em 2012 sobre o rendimento do estudante e as dificuldades dos professores em articular os conteúdos aos macrocampos, a redação do Documento Orientador do programa foi reformulada e na nova redação a formação continuada aparece como elemento básico para a efetivação do redesenho curricular no ensino médio.

Deste modo, a formação continuada passa a ser incentivada no ensino médio, surgindo assim o Pacto Nacional de Fortalecimento do Ensino Médio (Sismédio) ${ }^{7}$, como uma ação articulada ao Redesenho Curricular do Programa Ensino Médio Inovador para aperfeiçoar o conhecimento do professor e fortalecer a prática inovadora no trabalho com a integração curricular ${ }^{8}$ na atividade profissional.

Mais uma vez se reitera a importância da formação docente à melhoria e inovação curricular na escola de ensino médio, sendo esta concepção endossada a partir do entendimento de que "o ser professor, no contexto atual, exige certa ousadia aliada a diferentes saberes. Na era do conhecimento e numa época de mudanças, a questão da formação de professores vem assumindo posição de urgência nos espaços escolares". PERRENOUD (2001, p. 135-193).

Sob o enfoque dessa perspectiva, foram intensificadas alterações no Plano Nacional de Formação de Professores do Magistério da Educação Básica criado em 2009, o qual mobilizou o Sistema Educacional Brasileiro através do Conselho Nacional de Educação (CNE) e do consenso entre especialistas do Ministério da Educação (MEC), das secretarias municipais e estaduais, bem como das universidades e instituições públicas de ensino a buscar maior incentivo à prática de formação inicial e continuada no ensino médio, para assegurar melhor qualificação profissional aos docentes dessa etapa de escolaridade.

Cabe lembrar que o olhar da política educacional brasileira direciona-se também para a formação inicial do professor, que chega às escolas para ensinar os estudantes do ensino médio. Nesse caso, o segundo Plano Nacional de Educação (PNE 2014-2024) sancionado em 2014, atribui relevância à formação docente, quando na meta 16 (estratégia 16.2) ressalta a preocupação com a formação de professores para atender aos objetivos da educação básica diante das demandas educacionais que chegam à escola na sociedade contemporânea. Dessa forma, determina que a politica educacional brasileira deva 
“(...) consolidar uma política nacional de formação de professores e professoras da educação básica, definindo diretrizes nacionais, áreas prioritárias, instituições formadoras e processos de certificação das atividades formativas" (PNE, 2014, p.57).

As mudanças propostas para o ensino médio e para a formação inicial e continuada, sobretudo de 2009 até hoje reiteram a necessidade de formação docente, como forma de redefinir o novo papel do professor frente às novas exigências quanto à função social da escola. De acordo com essa nova concepção, o trabalho formativo precisa incluir tanto o domínio teórico do conhecimento profissional, quanto a capacidade de mobilizar o professor nas mais diversas práticas sociais, buscando espaços para a produção de subjetividades, num processo de reflexão sobre a própria prática. Nesse caso, o docente passa a ter a "compreensão de que ser um sujeito em formação pressupõe usar conscientemente o saber, o saber-fazer e o saber em função de um projeto específico" (JOSSO, 2004, p.86).

Portanto, a reconfiguração dos processos de formação profissional do professor passa, dentre outras questões, pela "necessidade de se compreender e atuar na educação dispondo da apropriação do conhecimento e de autonomia na forma de aplicá-lo no cotidiano escolar; com a atividade docente atuando como prática social" (NÓVOA, 1995, p. 76).

Nessa mesma linha de pensamento, Silva (2004) adverte que a formação docente é uma atividade inerente ao desenvolvimento profissional, pois a questão fundamental diz respeito não apenas ao fato de ser necessário melhorar as práticas formativas, mas de realizá-las de forma diferente. Assim pode-se dizer que a mudança na postura do professor e na atuação de seu papel no cotidiano de trabalho é, hoje, uma exigência da própria formação profissional. Nesse contexto, não basta simplesmente transferir os modelos de ensino e aprendizagem escolar para a formação de professores, por melhor que sejam uma vez que

Não basta tratar os professores como alunos que aprendem conteúdos cujo uso não é imediato e nem contextualizado; nem tão pouco organizar as ações tendo como apoio exclusivamente a informação teórica sobre a prática pedagógica. É preciso recriar as formas convencionais de ensino e aprendizagem para torná-las adequadas às peculiaridades da formação de professores (SILVA, 2004, p. 85).

Parafraseando Josso (2004), a política educacional brasileira, ao estimular a formação continuada e inicial de professores em suas ações educacionais, entende que a vivência do processo de formação atual exige dos docentes o entendimento de que

formar-se profissionalmente implica tomar consciência da "experiência" de onde cada um de nós retira lições e aprende coisas; consciência que emerge referenciada em pessoas, grupos, situações e acontecimentos que fazem parte de nosso percurso de vida pessoal e profissional (JOSSO, 2004, p. 91). 
Diante das novas demandas de ensino e aprendizagem, repensar a prática pedagógica e inovar a metodologia do ensino e da aprendizagem nos momentos de formação docente parecem ser os pilares necessários à efetivação de mudanças significativas no rendimento escolar do ensino médio.

\section{Considerações finais}

Com base nos estudos teóricos realizados neste trabalho de pesquisa, parece oportuno ressaltar que, no conjunto das mudanças curriculares que vêm sendo implementadas pela política educacional brasileira através do Ministério de Educação e Cultura (MEC), da década de 1990 aos dias atuais para o ensino médio, a oferta de formação inicial e continuada aparece associada aos indicadores de melhoria da qualidade desse ensino na escola pública.

Nesse sentido, percebe-se que um dos aspectos comum em todos os documentos curriculares estudados (Ldben, Pcnem, Dcnem Ocnem, PNE) é a perspectiva de atualização e adequação da prática docente às novas formas de ensinar e aprender, disponibilizadas pelo avanço da ciência e tecnologia para o ensino médio na sociedade contemporânea.

Acrescenta-se a isso que as Diretrizes Curriculares propostas pela política educacional brasileira para o ensino médio, atualmente Dcnem (2012), seja nos programas e projetos, seja nos referenciais curriculares nacionais, trazem a perspectiva da atualização e inovação da prática docente pelo viés da formação inicial e continuada, bem como de orientações metodológicas diversificadas. Nessa perspectiva, a filosofia educacional dessas diretrizes tem o intuito de orientar o professor do ensino médio a repensar e inovar a prática pedagógica, a fim de que possa se materializar no processo de ensino e aprendizagem, uma prática dinâmica e inovadora, capaz de estimular o estudante a atuar como protagonista na construção do próprio conhecimento, dentro e fora da escola.

Assim, há necessidade de continuar se investigando as emergências da formação docente e suas implicações no processo de ensinar e de aprender no ensino médio, pois embora a legislação brasileira venha estimulando a formação docente como elemento viabilizador de integração curricular e de melhoria do desenvolvimento e atuação profissional, ainda há muito a se fazer para que a formação docente, nesse nível de ensino, atenda as novas perspectivas pedagógicas e, sobretudo, de aprendizagem propostas pela política educacional brasileira da década de 1990 aos dias atuais.

Recebido em fevereiro de 2016 e aprovado em abril de 2016 


\section{Notas}

1 “epistemologia da complexidade no seu sentido próprio é a capacidade de interligar, ou seja, a capacidade de juntar e construir aquilo que nunca deveria ser separado. E em relação a educação, ao conhecimento e a formação afirma que o conhecimento do conhecimento não pode fechar-se em fronteiras estritas, pois o conhecimento não é insular, mas peninsular e, para conhece-lo, temos que liga-los ao contexto mais amplo, do que faz parte. As partes devem ser interligadas entre si". (MORAN, 2000, p.26).

2 O Plano de Metas Compromisso Todos pela Educação, instituído pelo Decreto Federal no 6.094, de 2007 para ser implementado pela União, tido como o "carro-chefe" (SAVIANI, 2007, p. 3) do PDE, constitui-se em uma estratégia utilizada para regulamentar o regime de colaboração com municípios, estados e Distrito Federal, com a participação das famílias e da comunidade, visando à mobilização social pela melhoria da qualidade da educação básica.

3 A contextualização tem muito a ver com a motivação do aluno, por dar sentido àquilo que ele aprende, pois o olhar volta-se para o contexto sócio histórico e cultural do aluno. (LIBÂNEO, 1999, p. 59)

4 Movimento exercido dentro das disciplinas e entre elas, visando integrá-las (LENOIR, 1998, p.87).

5 Diz respeito à compreensão de que educação enquanto processo formativo deve atuar pelo desenvolvimento dos indivíduos nas suas múltiplas dimensões: física, intelectual, social, emocional e simbólica. (Núcleo de estudos e pesquisas sobre criança e adolescente (NECA, 2012).

6 Macrocampos.

7 Portaria de $\mathrm{n}^{\mathrm{o}} 1.140$ de 22 de novembro de 2013

8 Aqui entendida como a articulação interdisciplinar entre os conteúdos, os eixos estruturantes do ensino médio e os macrocampos na práxis educativa do ensino médio ( BRASIL, MEC/SEB, 2014).

\section{Referências}

BRASIL. Ministério de Educação e Cultura. Lei n.․9 9394, de 20.12.96, Estabelece as diretrizes e bases da educação nacional", in Diário da União, ano CXXXIV, 1996.

Ministério de Educação e Cultura (MEC) Diretrizes Curriculares Nacionais Gerais da Educação Básica. Ministério da Educação. Secretária de Educação Básica. Diretoria de Currículos e Educação Integral. Brasília: MEC, SEB, DICEI, 2013.

. Ministério da Educação (MEC), Secretaria da Educação Básica (SEB). Parâmetros Curriculares Nacionais para o Ensino Médio. Brasília: MEC, 2000.

- Ministério da Educação. Diretrizes Curriculares Nacionais para o Ensino Médio. Resolução CNE/CEB nํำ, de 2012.

.Ministério da Educação e Cultura (MEC). Plano Decenal de Educação 2014- 2024.

Brasília, MEC, 2014.

1999.

. Parâmetros Curriculares Nacionais: terceiro e quatro ciclos - Introdução. Brasília: MEC/SEF,

DELIZOICOV, D., ANGOTTI, J. A.; PERNAMBUCO, M. M. Ensino de ciências: fundamentos e

métodos. São Paulo: Cortez, 2002. 
GATTI, B.A.; BARRETO, E.S.S. Professores: aspectos de sua profissionalização, formação e valorização social. Brasília, DF: UNESCO, 2010.

JOSSO, M. C. Experiências de Vida e Formação. São Paulo, Cortez, 2004.

LENOIR, Yves. Didática e Interdisciplinaridade: uma complementaridade necessária e incontornável. In: FAZENDA, Ivani (org.) Didática e interdisciplinaridade. São Paulo: Papirus, 1998.

LIBÂNEO, José Carlos. Didática. São Paulo: Editora Cortez, 1999.

LIBÂNEO, José Carlos; PARREIRA, Lelis. Pedagogia, como ciência da educação. Cadernos de Pesquisa, São Paulo, v. 37, n.131, mar/ago., 2007.

MORAN, José Manuel et al. Novas tecnologias e mediação pedagógica. 6. ed. Campinas: Papirus, 2000.

NÓVOA A. As ciências da educação e o processo de mudanças. São Paulo, Cortez, 1995.

NUÑEZ, I. B; RAMALHO, B. L. a noção de competência nos projetos pedagógicos do ensino médio: reflexões na busca de sentidos. In: Fundamentos do Ensino- aprendizagem das Ciências Naturais e da Matemática. Porto Alegre: Sulina, 2004.

PERRENOUD, Philippe. A ambiguidade dos saberes e da relação com o saber na profissão de professor. In: Ensinar a agir na urgência, decidir na incerteza, do mesmo autor. Porto Alegre: Artmed Ed, 2001.

PIMENTA, Selma Garrido. Didática e Formação de Professores: percursos e perspectivas no Brasil e em Portugal. São Paulo: Cortez, 2006.

RAMALHO, B.; NUÑEZ, I., y GAUTHIER, C. Formar o professor, profissionalizar o ensino: perspectivas e desafios. Porto Alegre: Sulinas, 2003.

SILVA, J. A Natureza e a especialização da educação: subsídios à formação do educador. Brasília: MEC/INEP, 2004.

TARDIF, M.; LESSARD, C. O trabalho docente: elementos para uma teoria da docência como profissão de interações humanas. Petrópolis: Vozes, 2005.

WEBER, Marianne. Weber uma biografia. São Paulo: Casa Jorge Editorial, 2003. 